\title{
RELATOS DE EXPERIÊNCIAS DE DISCENTES NA DISCIPLINA DE EDUCAÇÃO AMBIENTAL COMO INSTRUMENTO EM GESTÃO EM PROGRAMA DE MESTRADO ACADÊMICO DA UNIFAL (MG)
}

\author{
Cássio Alexandre Dantas ${ }^{1}$ \\ Carla Beatriz Amaral Rossi ${ }^{2}$ \\ Cynthia Spaggiari ${ }^{3}$ \\ Gustavo Andrade Godoy ${ }^{4}$ \\ José Borges Carvalho ${ }^{5}$ \\ Luís Felipe Gouvea ${ }^{6}$ \\ Priscila Vilela Borges ${ }^{7}$ \\ Rosiney Aparecida Paula Dias ${ }^{8}$ \\ Rafaela Macedo Soares ${ }^{9}$ \\ Raíssa Tavares ${ }^{10}$ \\ Adriana Maria Imperador ${ }^{11}$
}

Resumo: O presente artigo tem como finalidade relatar as experiências de discentes participantes da disciplina Educação Ambiental como Instrumento de Gestão, do curso de Pós-Graduação em Ciência e Engenharia Ambiental da Universidade Federal de Alfenas-MG no segundo semestre do ano de 2014. A disciplina foi cursada por dez alunos de formações distintas e áreas profissionais diversas. A metodologia proposta proporcionou a apresentação de atividades complementares sobre diferentes pontos de vista, com temas referentes a cada área de formação dos discentes e à sua relação com a Educação Ambiental. A avaliação dos discentes foi positiva considerando à eficiência da proposta apresentada na grade curricular da pós-graduação.

Palavras-chave: Educação Ambiental; Meio Ambiente; Interdisciplinaridade.

\footnotetext{
1,2 Universidade Federal de Alfenas (ICT/UNIFAL/Campus Poços de Caldas).

${ }^{3}$ Universidade Federal de Alfenas (ICT/UNIFAL/Campus Poços de Caldas). Email: cyspaggiari@gmail.com

${ }^{4}$ Universidade Federal de Alfenas (ICT/UNIFAL/Campus Poços de Caldas). Email: gugodoy@yahoo.com.br

${ }^{5}$ Universidade Federal de Alfenas (ICT/UNIFAL/Campus Poços de Caldas). Email: jose.carvalho@danone.br

${ }^{6}$ Universidade Federal de Alfenas (ICT/UNIFAL/Campus Poços de Caldas). Email: Ifcgouveia@hotmail.com

${ }^{7}$ Universidade Federal de Alfenas (ICT/UNIFAL/Campus Poços de Caldas). Email: priscilagborges@gmail.com

${ }^{8}$ Universidade Federal de Alfenas (ICT/UNIFAL/Campus Poços de Caldas). Email: rosi_paulaaparecida@hotmail.com

${ }^{9}$ Universidade Federal de Alfenas (ICT/UNIFAL/Campus Poços de Caldas). Email: rafa_msoares@yahoo.com.br

${ }^{10}$ Universidade Federal de Alfenas (ICT/UNIFAL/Campus Poços de Caldas). Email: tavaresraissa@ig.com.br

${ }^{11}$ Universidade Federal de Alfenas (ICT/UNIFAL/Campus Poços de Caldas). Email: adrianaimperador@yahoo.com.br
} 


\section{Introdução}

Ao longo dos anos a Educação Ambiental (EA) vem ganhando espaço no cenário acadêmico. Inserir o tema EA neste contexto renova oportunidades para a discussão acerca da conscientização e da responsabilidade de cada um perante o meio ambiente.

Ela é definida como o conjunto de processos por meio dos quais o indivíduo e a coletividade constroem valores sociais, conhecimentos, habilidades, atitudes e competências voltadas para a conservação do meio ambiente (Brasil, 1999) atendendo as premissas apresentadas pela Constituição Federativa do Brasil, que determina que o meio ambiente é um bem de uso comum do povo, essencial à sadia qualidade de vida e sua sustentabilidade (BRASIL, 1989).

Segundo Branco (2003) a Educação Ambiental tem como objetivos primordiais 0 autoconhecimento, a socialização e o conhecimento para proporcionar a mudança de comportamentos. Sua aplicação da EA em sala de aula é considerada um instrumento para a tentativa de sanar ou diminuir os problemas ambientais (BRASIL, 1999).

O ensino superior aparece muitas vezes como um cenário privilegiado em relação à aplicação de práticas de Educação Ambiental, devido as suas características voltadas ao ensino pesquisa e extensão. Cursos voltados à temática ambiental composto por corpo docente que valorize o diálogo e a interdisciplinaridade podem desenvolver a competência de ações articuladas que valorizem a solução de problemas e incentivar a sustentabilidade em sistemas naturais.

Segundo a Política Nacional de Educação Ambiental (PNEA), a Educação Ambiental deve se apresentar como um componente essencial e permanente da educação nacional e estar presente em todos os níveis e modalidades do processo educativo (PNEA, 1999). Esta afirmação inclui os programas de pós-graduação, principalmente os que apresentam um caráter ambiental.

Tendo em vista esta proposta, o Programa de Pós-Graduação em Ciência e Engenharia Ambiental (PPGCEA) foi recomendado no ano de 2011 para o nível de Mestrado pela Universidade Federal de Alfenas - campus Poços de Caldas e teve sua primeira turma no segundo semestre do ano seguinte (2012) (PPGCEA, 2014).

O Programa conta com três linhas distintas de pesquisa, que são: Monitoramento Ambiental, Planejamento e Gestão de Recursos Hídricos e Tratamento de Águas Residuárias. Devido ao seu caráter interdisciplinar, os alunos aprovados por meio de processo seletivo podem apresentar áreas de formação em diversas graduações distintas.

Dentre as disciplinas oferecidas no programa, está a unidade CEA015 Educação Ambiental como Instrumento de Gestão, com carga horária de 60 horas, que trabalha as propostas da Política Nacional de Educação Ambiental.

revista brasileira educação ambiental 
Este artigo apresenta a percepção dos alunos inscritos na disciplina no segundo semestre do ano de 2014, apontando críticas em relação ao método de ensino e as práticas em diversas áreas de formação dos discentes.

\section{Metodologia}

A Disciplina foi realizada em encontros semanais de quatro horas, no período vespertino, nas instalações da Universidade Federal de Alfenas no Campus Avançado de Poços de Caldas, MG.

O Programa de Ensino aprovado pelo colegiado do PPGCEA propôs algumas intervenções iniciais com apresentação de conteúdos referentes à Legislação, Conceitos e Práticas de EA.

Em seguida cada discente selecionou um tema relacionado à sua área de formação, associando algumas ações a práticas ambientais, utilizando materiais de apoio disponíveis na Universidade e ferramentas didáticas como produção de slides, mapas conceituais, revistas, vídeos, dentre outras. Ao final do semestre foi proposto um questionário de avaliação, contendo cinco questões a respeito do aproveitamento da disciplina.

\section{Resultados e Discussões}

Os alunos inscritos na disciplina eram graduados em diversas áreas do conhecimento, sendo elas arquitetura e urbanismo, geografia, biologia, bacharelado em ciência e tecnologia, engenharia ambiental, direito, administração de empresas, licenciatura em ciências, química industrial e medicina veterinária.

Os temas selecionados por estes discentes foram Educação Patrimonial, ABC do Meio Ambiente, Alfabetização Ecológica, Importância do Protagonismo Juvenil e do Sentimento de Pertença na Educação Ambiental, Os Rios Voadores, Educação Ambiental no Gerenciamento de Resíduos, Os 3 R's na Construção Civil, Educação Ambiental no Ensino Fundamental e O Tratamento de Resíduos na Indústria Cervejeira.

O tema abordado pela arquiteta foi Educação Ambiental e Patrimonial. Para embasar a discussão foi escolhido artigo de Sandra C. A. Pelegrine: Cultura e Natureza: os desafios das práticas preservacionistas na esfera do patrimônio cultural e ambiental, publicado na Revista Brasileira de História em 2006. O artigo destaca como as relações entre natureza e cultura tem se manifestado nas concepções do patrimônio e norteado ações no âmbito da educação patrimonial e ambiental, tomadas como instrumentos para a construção da cidadania e do desenvolvimento sustentável (PELEGRINE, 2006).

Foi realizada avaliação crítica sobre diversos assuntos relacionados ao tema e a Educação Ambiental sobre os subtemas turismo cultural, reabilitação das áreas degradadas, manejo adequado do meio ambiente, costumes e Revbea, São Paulo, V. 12, № 2: 56-66, 2017. 
conhecimentos populares, políticas públicas, salvaguarda de bens, identidade cultural, tradições orais, o conceito de pertencimento, patrimônio material e imaterial, restauração e a importância da escuta dos habitantes envolvidos em qualquer projeto ou ação.

O próximo tema abordado pela professora de ciências foi "O $A B C$ do meio ambiente", por meio de recurso áudio visual, em que foi colocada em pauta a falta de chuva, escassez da água, desmatamento, queimadas, poluição, entre outras, isto é, inúmeros problemas ambientais visíveis e notáveis na sociedade. Também foi discutida a metodologia de "Alfabetização Ecológica" descrita por Capra (2006).

A docente em pedagogia selecionou diversas ações e projetos que auxiliam e conscientizam a população de suas atitudes, como as mudanças que ocorreram através de gerações ao meio ambiente e descobertas científicas que ao longo do tempo se tornaram nocivas ao ser humano. Além disso, trouxe para sala o texto "O que é o meio ambiente", aplicando, em seguida, a "Pegada Ecológica", dinâmica que tem por intuito calcular o impacto gerado pela nossa intervenção na natureza.

O tema abordado pelo geógrafo foi à relação da alimentação no processo de educação. Utilizou-se como principal referência alguns fragmentos do livro escrito por diversos autores, entre eles Fritjof Capra, intitulado Alfabetização Ecológica: a educação das crianças para um mundo sustentável. Como texto para debate recorreu-se ao prefácio à edição brasileira da obra supracitada escrito por Miriam Dualibi. A ideia principal contida nesta obra trazida por Capra é a de que a definição que se prega sobre sustentabilidade não ultrapassa o limite da exortação moral, dado que tal definição não nos indica meios de como se levar um estilo de vida sustentável para com o meio ambiente (CAPRA et al. 2006). Após a discussão deste texto, o tema Alfabetização Ecológica foi trabalhado com o auxílio do capítulo do livro de Capra, redigido pela autora Alice Walters, "Os valores da "fast food" e os valores da "slow food". De forma pontual a autora descreve os males advindos da "fast food", abordando ideias torpes deduzidas pelos consumidores no ato da alimentação com este tipo de comida. Conceitos errôneos como: a inesgotabilidade do solo fértil, a abundância de recursos naturais, a ilusão das propagandas entre outros. Alice Walters segue seu texto fazendo um contraponto com a "slow food", seus benefícios e ensinamentos: o respeito aos produtores e a produção de alimentos de acordo com a capacidade ambiental. Tais conceitos foram introduzidos à aula com uma apresentação de slides.

Por fim, foi destacado como uma ideia prática a ser desenvolvida nas escolas o projeto da mesma autora intitulado "O pátio comestível da escola". 0 que uma horta residente em uma escola pode ensinar? Alice responde: "a partir da horta, da cozinha e da mesa, você aprende empatia - um com o outro e com toda a criação; você aprende compaixão; você aprende paciência e autodisciplina. Um currículo que ensina essas lições dá às crianças uma orientação para o futuro - e dá a elas esperança". 
O tema abordado pelo professor de ciências foi "Importância do Protagonismo Juvenil e do Sentimento de Pertença na Educação Ambiental". A aula iniciou com a apresentação do "Vídeo Genial sobre a Juventude" que retrata as características da juventude ao longo do tempo, desde a década de 1950 até a atualidade, seguida de discussão sobre o conteúdo.

Em seguida, foi distribuído o texto "O que é o Protagonismo Juvenil" de Maria Eleonora D. Lemos Rabêllo, seguido da apresentação sobre o conceito e a importância do protagonismo juvenil e do sentimento de pertença, com enfoque na relação entre esses conceitos e a Educação Ambiental. Destaque para o grande potencial de trabalho do jovem e a necessidade que ele construa o próprio conhecimento através de seu protagonismo (COSTA, 2000).

Dando continuidade aos temas foi apresentado pela Engenheira Ambiental o Projeto dos Rios Voadores, que tem por objetivo realizar as análises das amostras de vapor de água, a fim de caracterizar a sua origem e monitorar as trajetórias dessas enormes massas de ar.

Dessa maneira, foi apresentado todo o histórico do projeto, as análises realizadas, a definição de como ocorre o fenômeno e quais as relações entre o desmatamento e queimadas na Amazônia sobre o balanço hídrico do país e sua participação no panorama das mudanças climáticas. Com base no texto apresentado "Um Rio que Flui pelo Ar" de Ricardo Zorzetto, inciou-se uma discussão a respeito da visão que se têm em relação aos recursos hídricos no país, quais são as medidas adotadas de preservação, os principais instrumentos de gestão e o que deve ser melhorado (ZORZETTO, 2009).

Em seguida, foram apresentados os projetos de Educação Ambiental realizados pelo programa dos Rios Voadores e os materiais didáticos que estão disponíveis para acesso de todos no próprio site do programa, de forma que esse fenômeno de extrema importância tenha alcance em todas as regiões do país e seja visto de uma maneira mais consciente e comprometedora.

O tema abordado pela outra discente, também formada em Engenharia Ambiental, foi "Educação Ambiental no Gerenciamento de Resíduos". Esse assunto foi escolhido pelo fato de que a conscientização da população acerca da Gestão de Resíduos é hoje um grande desafio, dessa forma, a Educação Ambiental torna-se fundamental, uma vez que proporciona mudanças de comportamento e conceitos.

A aula foi baseada em um estudo de caso realizado na cidade de ljuí/RS cujo texto se intitula "Gerenciamento de Resíduos Sólidos - A importância da educação ambiental no processo de implantação da coleta seletiva de lixo - O caso de ljuí/RS", esse texto pode ser encontrado na Revista Eletrônica em Gestão, Educação e Tecnologia Ambiental. O texto foi lido e discutido entre todos os discentes presentes e em seguida foi apresentado o projeto socioambiental Cidadão Consciente, da cidade de Nova Rezende/MG (PERSICH et al., 2011). 
Esse projeto busca mostrar a importância de práticas como a separação de resíduos e o valor que esses materiais podem ter através da conscientização da população. Ele trabalha com a "troca" de materiais recicláveis por alimentos e funciona da seguinte forma: o cidadão leva ao posto de troca os materiais recicláveis onde estes são pesados e valorados de acordo com o tipo de material, o cidadão então recebe um vale com o valor do material e pode trocá-lo, propiciando aos habitantes alimentos a baixo custo além de atuar na consciência ambiental.

O tema abordado pela outra arquiteta da disciplina destaca "Os 3R's na Construção Civil". Dada a importância da redução, reutilização e reciclagem destes rejeitos, que conta com a Resolução no 307, de 5 de julho de 2002 - Lei CONAMA, para implementar diretrizes que efetivem a minimização dos impactos ambientais gerados por este processo.

A apresentação do tema foi feita através de vídeos, texto e uma cartilha para leitura instrutiva sobre a gestão e o gerenciamento sem desperdícios no canteiro de obras. O primeiro vídeo apresentado, Reciclagem de Resíduos da Construção Civil - Globo Ecologia (2012), discute a problemática da destinação dos resíduos sólidos da construção civil, revelando que este, é responsável por quase $70 \%$ da massa residual urbana. O segundo vídeo: Ecosolidos Programa Reciclagem (2011); mostra a classificação dos resíduos e o funcionamento de uma usina de reciclagem em Goiás, que após fazer a triagem dos materiais recebidos dos descartes, enviam para o processamento onde é possível transformá-los em novos materiais, que serão reaproveitados na própria construção civil. Por fim, o terceiro vídeo, Cidade $100 \%$ Sustentável na Alemanha, (2008), mostra como Freiburg se tornou um exemplo. Com níveis de emissão de carbono praticamente igual a zero e construções absolutamente projetadas para aproveitar todas as condições naturais oferecidas pelo clima e pela geografia da cidade, transformando assim, todas estas características em algum tipo de aproveitamento. O texto da autora Carolina Machado e Bedim, descreve sobre a importância da redução, reutilização e a reciclagem dos resíduos sólidos, assim como sua destinação.

Segundo Barreto (2005),

o novo paradigma da construção civil fundamenta-se na integração dos seus principais agentes. Integrar significa compartilhar responsabilidades; recursos humanos e financeiros; conhecimento e tecnologia; instrumentos; e esforços, minimizando os impactos ambientais da cadeia produtiva da indústria da construção. Dada esta realidade, a adequação do princípio dos 3R's se torna uma necessidade para a diminuição da problemática dos resíduos.

O tema abordado pelo administrador de empresas foi "Educação Ambiental como Instrumento para Coleta Seletiva e Reciclagem". Esse assunto foi escolhido pelo fato de que a população necessita de uma maior interação acerca da nova política de gestão de resíduos, em rigor no Brasil, a Lei no

revista brasileira educação ambiental 
12.305/10 (PNRS). Esta conceituação se faz necessária, pois a Educação Ambiental traz consigo uma mudança de comportamento e atitudes perante a responsabilidade de cada um para com a geração, gestão e destinação final de resíduos sólidos.

A aula foi baseada em um estudo de caso realizado em Goiânia/GO cujo texto se intitula "A Educação Ambiental, a Coleta Seletiva e a Reciclagem no Condomínio Edifício Veredas, Goiânia/GO", dos autores Christiano Ferreira Dias e Divino Pinheiro Filho. Este projeto busca mostrar a importância da coleta seletiva e a reciclagem de resíduos sólidos que são consideradas práticas necessárias capazes de um costume abusivo onde o meio ambiente é o responsável pela eliminação dos resíduos produzidos pelo ser humano.

O tema abordado pela professora de ciências foi a Educação Ambiental no ensino fundamental. Esta etapa do ensino tem duração de nove anos e é obrigatório para crianças de 6 a 14 anos, sendo regulamentado pela Lei de Diretrizes e Bases da Educação de 1996 (Brasil, 1996). A matriz básica do Ensino Fundamental é obrigatória e inclui as disciplinas: Língua Portuguesa; Matemática; conhecimentos do mundo físico e natural e da realidade social e política, principalmente a do país.

A Educação Ambiental ser aplicada de maneira formal e não formal. De acordo com a experiência profissional em escolas públicas da região, a discente aponta para a carência da aplicação da EA no ensino formal, de maneira que esta possa desenvolver e incutir nos estudantes em uma consciência crítica sobre a problemática ambiental.

Para elucidar a problemática da educação formal no país, foi utilizado o embasamento teórico de Paulo Freire, educador e filósofo, e de Ivan Illich, filósofo, que se identificam ao defenderem a desescolarização da educação e propunham a criação de círculos de cultura e deres de convivialidade para educar, com o intuito de alcançar uma sociedade solidária, inclusiva e não opressora. Tanto Freire como Illich se aproximam ao visualizar a escola como um veículo do capitalismo para eternizar a dominação e o poder de uma determinada classe social.

Para a exposição do tema, foram abordados temas explorando o pensamento filosófico de Ivan Illich em relação ao sistema educacional convencional e exemplificando a educação construída por meio da Pedagogia da Roda; e o artigo "Diálogo de Illich e Freire em torno da educação para uma nova sociedade" de Peri Mesquita (MESQUITA,2007).

O tema abordado pelo químico industrial foi "O Tratamento de Resíduos na Indústria Cervejeira". No início da aula, houve uma explicação resumida sobre a fabricação de cervejas, tanto a nível industrial como artesanal. Foram levados os principais insumos (cevada, malte de cevada, água, lúpulo e levedura) da fabricação de cervejas para que os ouvintes tivessem uma maior noção sobre o assunto (MOREIRA, 2013). 
Logo após, um texto resumido do trabalho "Gestão ambiental na cervejaria Pará: um estudo de caso" (RABELO et al., 2013) possibilitou uma associação entre a disciplina Educação Ambiental como Instrumento de Gestão e o tema secundário da apresentação, que foi a produção cervejeira. $O$ texto mostra que é possível tomar certas atitudes como o aproveitamento de resíduos de produção e aplicação do "tripé da sustentabilidade empresarial", que leva em consideração três fatores, o ambiental, o social e o financeiro na construção da sustentabilidade empresarial.

Por fim, uma matéria sobre a autuação de uma grande cervejaria foi apresentada, devido a vazamento de óleo, lançamento indevido de efluentes e a realização de uma obra numa área de mais de 2 mil metros quadrados sem o Estudo de Impacto Ambiental e o Relatório de Impacto no Meio Ambiente (EIA/Rima) além da permissão do Instituto Estadual do Ambiente (INEA) (GOULART, 2010).

Com isso, têm-se as apresentações de todos os discentes participantes da disciplina finalizadas. Como proposto inicialmente, foi realizada um breve estudo da percepção dos discentes em relação à metodologia aplicada (Figura 1), os temas apresentados (Figura 2), o aproveitamento dos temas na área de conhecimento (Figura 3), a interdisciplinaridade apresentada pela disciplina (Figura 4) e a aplicabilidade do método (Figura 5), que são apresentados a seguir:

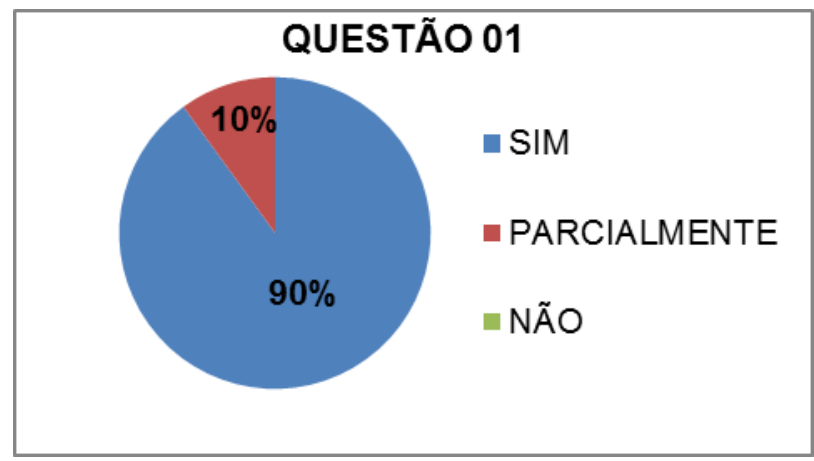

Figura 1: a metodologia aplicada foi eficiente para atingir os objetivos da disciplina?

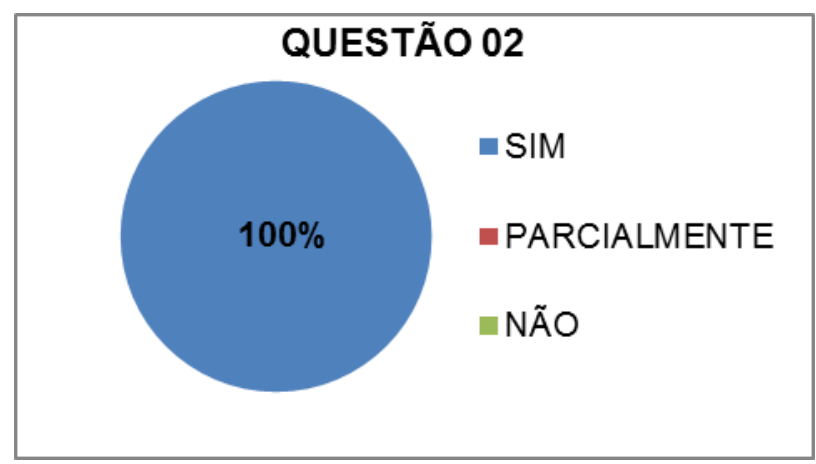

Figura 2: os temas apresentados estavam dentro da proposta? 


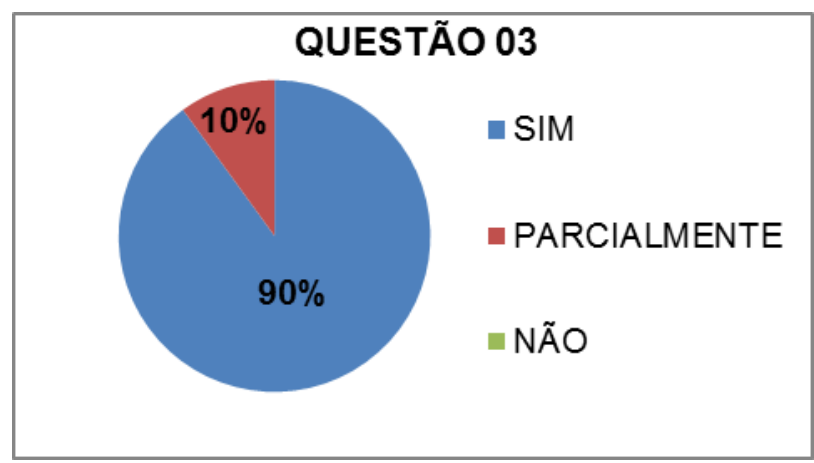

Figura 3: os temas apresentados agregaram valor á sua área de conhecimento?

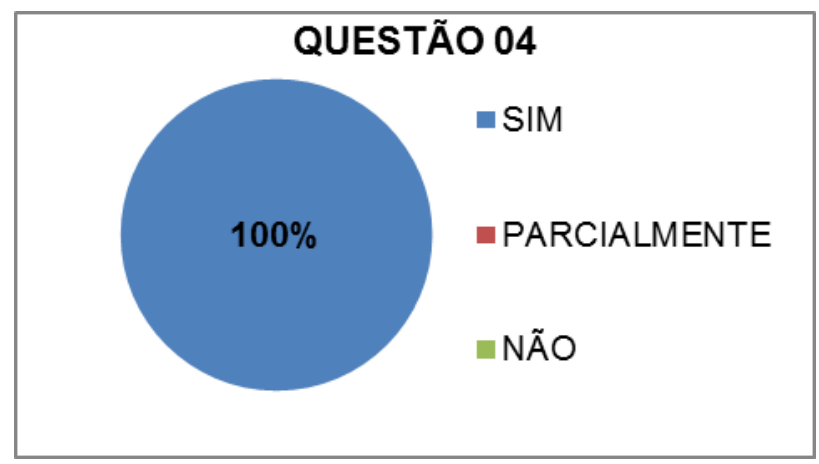

Figura 4: você conseguiu realizar a interdisciplinaridade dos temas com sua área de formação?

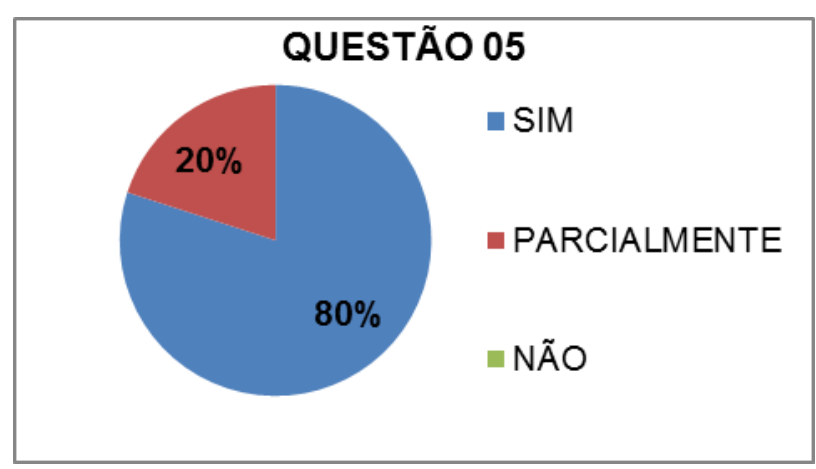

Figura 5: foi possível aplicar os conhecimentos adquiridos no seu dia-a-dia?

Foram também discutidas algumas sugestões para a disciplina a serem aplicadas para as próximas turmas, como troca de material didático entre os alunos dos trabalhos feitos e dos artigos relacionados à área de cada um; duas apresentações por aula; a elaboração de um plano de ação a ser executado e de um material pedagógico de Educação Ambiental; o estabelecimento de um calendário de apresentações e tempo necessário para desenvolver todas as atividades, de forma a reservar aulas livres para fomentar discussões de alguns tópicos da disciplina. 


\section{Conclusões}

A Educação Ambiental está em pauta como assunto predominante e de suma importância para a sustentabilidade do planeta. Assunto que desperta entre profissionais de várias áreas a necessidade simultânea de conhecer meios que possam criar responsabilidade e a interação de cada indivíduo, de forma constante e contínua, para que se possa amenizar tal situação como cidadãos. Foram desenvolvidos na disciplina apresentada, trabalhos e debates relacionados a áreas diversas de forma interdisciplinar, estimulando 0 envolvimento de todos nesta temática. A formação diversificada dos integrantes do curso proporcionou a abordagem de vários assuntos. A apresentação destes seminários evidenciou a importância que cada profissional tem no desenvolvimento de técnicas, planejamentos, organização e administração de ações vinculadas a Educação Ambiental e Sustentabilidade para a conservação dos recursos naturais. Na percepção dos discentes, a forma com que foi conduzida a disciplina "Educação Ambiental como Instrumento de Gestão" foi eficiente para alcançar os objetivos propostos.

Educar é a maneira mais viável para que se possa assegurar um futuro mais sustentável. Através da educação, é possível informar, sensibilizar e comprometer o indivíduo a diminuir os impactos ambientais, a fazer uso dos recursos com a responsabilidade da preservação dos bens renováveis da natureza e também daqueles que não o são. Unindo as várias áreas de conhecimento é possível promover uma gestão mais equilibrada, com profissionais devidamente habilitados.

\section{Referências}

BARRETO, I. M. C. B. N. Gestão de resíduos na construção civil. Aracaju: SENAI/SE; SENAI/DN; COMPETIR; SEBRAE/SE; SINDUSCON/SE, 2005. 28p.

BRANCO, S. Educação Ambiental: metodologia e prática de ensino. Rio de Janeiro: Dunya, 2003.

BRASIL. Lei n. 9795, de 27 de abril de 1999. Dispões Sobre a Educação Ambiental, institui a Política Nacional de Educação Ambiental e dá Outra Providências. Diário Oficial [da] República Federativa do Brasil. Brasília, DF, 27 de abril 1999a. Disponível em: $<$ http://www.planalto.gov.br/ccivil 03/leis/l9795.htm>, acessado em 03/12/2014.

BRASIL. Lei de Diretrizes e Bases da Educação Nacional. Lei número 9394, 20 de dezembro de 1996.

Brasil. Constituição da República Federativa do Brasil. DF: Senado Federal: Centro Gráfico, 1988, 292p.

CAPRA, F; STONE, M.K.; BARLOW, Z. Alfabetização Ecológica: a educação das crianças para um mundo sustentável. São Paulo: Cutrix, 2006, 312 p. 
COSTA, A. C.G. Protagonismo juvenil: adolescência, educação e participação democrática.Salvador, Fundação Odebrecht, 2000.

GOULART, G. Cervejaria é autuada por poluição ambiental. O Globo. Disponível em: <http://oglobo.globo.com/rio/cervejaria-autuada-por-poluicaoambiental-2957205>, acessado em 10/10/2015.

LOUREIRO, C.F.B. Proposta Pedagógica: Aspectos Históricos e Pedagógicos da Educação Ambiental no Brasil. TV Escola , 2008. p 03-09. ISSN 1982-0283.

MEC. RUPEA. Relatório Final da Pesquisa: Mapeamento da Educação Ambiental em instituições brasileiras de Educação Superior: elementos para discussão sobre políticas públicas. Brasília: MEC, 2005.

MESQUITA, P. Diálogo de Illich e Freire em torno da educação para uma nova sociedade. Contrapontos, volume 7, n.3, p. 549-563 - Itajaí, 2007.

MOREIRA, F.N. Gestão Ambiental Na Cervejaria Pará: Um Estudo De Caso. Revista Científica Semana Acadêmica. Fortaleza, ano MMXIII, №. 000024, 10/07/2013. Disponível em:<http://semanaacademica.org.br/gestao-ambientalna-cervejaria-para-um-estudo-de-caso>, acessado em 02/12/2014.

PELEGRINI, S.C.A. Cultura e natureza: os desafios das práticas preservacionistas na esfera do patrimônio cultural e ambiental. Revista Brasileira de História. São Paulo, v. 26, no 51, p. 115-140 - 2006.

PERSICH, J.C.; SILVEIRA, D.D. Gerenciamento de Resíduos Sólidos - A importância da educação ambiental no processo de implantação da coleta seletiva de lixo - O caso de ljuí/RS. Revista Eletrônica em Gestão, Educação e Tecnologia Ambiental, v. 4, p. 416-426, 2011. ISSN: 2236-1170

PRIGOGINE, I. O fim das certezas: tempo, caos e as leis da natureza. São Paulo: UNESP, 1996. 13. PPGCEA - PROGRAMA DE PÓS-GRADUAÇÃO EM CIÊNCIA E ENGENHARIA AMBIENTAL. UNIFAL, Alfenas - MG. Disponível em: < http://www.unifal-mg.edu.br/ppgcea/>, acessado em: 25/11/2014.

REBELO, C.L. MARTINS, L.C.C.; MOREIRA, F.N. SANTOS, T.L. Gestão ambiental na Cervejaria Pará: um estudo de caso. Revista Científica Semana Acadêmica. N.1, ed. 24, 2013. Disponível em: http://semanaacademica.org.br/system/files/artigos/gestaoambientalnacervejari aparaumestudodecaso.pdf, acessado em 10/10/2015.

RABÊLLO, M.E.D.L. O que é protagonismo juvenil. Centro de Defesa da Criança e do Adolescente Yves de Roussan (CEDECA/Bahia). Disponível em <http://www.cedeca.org.br/conteudo/noticia/arquivo/39DA691A-FD4ED119-3DAE60914B0999AE.pdf.>, acessado em 07/11/2014.

SILVA, M.L. A educação ambiental no ensino superior brasileiro: do panorama nacional às concepções de alunos (as) de pedagogia na Amazônia. Revista Eletrônica do Mestrado em Educação Ambiental. FURG, 2013.

ZORZETTO, R. Um rio que flui pelo ar. Revista Pesquisa FAPESP. São Paulo. p 62-63. 2009.

Revbea, São Paulo, V. 12, № 2: 56-66, 2017. 